\title{
Consumer Acceptance of Location Based Services in the Retail Environment
}

\author{
Iris Uitz \\ Graz University of Technology \\ Institute of Business Economics and Industrial Sociology \\ Kopernikusgasse 24/II, 8010 Graz, \\ Austria
}

\author{
Roxane Koitz \\ Graz University of Technology \\ Kopernikusgasse 24/II, 8010 Graz,
}

Austria

\begin{abstract}
Smartphones have become a commodity item. In combination with their seemingly infinite extensions through mobile applications, they hold great economic potential for businesses. Location Based Services (LBS) take advantage of their portability by providing relevant information to the user regarding their location. Utilizing the user's position to create personalized location-specific marketing messages enables businesses to yield value for their customers. The main objective of this paper is to identify factors, which influence the acceptance of LBS apps in the context of retail since there is a lack of research in this field. A qualitative research approach was chosen to investigate the relevant variables. Based on the conducted interviews, theories were derived and verified against further data retrievals. Similar to findings of previous research the factors ease of use (usability) and usefulness were confirmed as being crucial in forming consumers' attitudes.
\end{abstract}

Keywords-Location Based Services; Usability-Testing; Apps; Shopping-Apps; Mobile; Consumer Acceptance; Mobile Marketing

\section{INTRODUCTION}

Location Based Services (LBS) utilize a device's position in order to provide the consumer with personalized information. A widespread application of LBS is navigation systems. There are several methods on how to achieve the positioning of a mobile device. A common technique is to use satellite-positioning systems like the Global Positioning System (GPS). However, this method is not feasible for indoor navigation due to weakened signal strengths and inaccuracy. For the positioning indoors, two different approaches are generally applied. The first method uses a signal infrastructure consisting of Wi-Fi signals, for examples. The determination of the device's position can be calculated based upon signal strengths. The alternative is a dead reckoning approach using an inertial system. Those systems take a starting point and calculate the position based upon sensor measurements of acceleration and possibly other variables.

LBS are by far not limited to navigation; they provide the capabilities to be used for a large amount of purposes. Especially the creation of a service allowing an accurate positioning inside combined with smartphones poses unique opportunities for businesses. Owing to the portability of smartphones and their ubiquitous Internet access retailers can use them to market their products virtually whenever and wherever. By taking the user's location information into account, companies can create context specific offers and notifications. They hence ameliorate consumer targeting.
Location awareness is an especially interesting aspect, since more than half of the purchase decisions are made within the stores themselves [14]. In regard to this finding, location-based marketing strategies, addressing the consumer at the point of the purchase decision, do not only hold potential for the entrepreneur, but also create value for the consumer through relevant personalized messages. There are already several mobile applications integrating LBS in retail environments. Ma\$\$iv€, as described in [2], for instance, is an intelligent mobile grocery shopping assistant app and web application. The system is based on the user's mobile shopping list and is able to navigate the consumer to items on the list within the store. Furthermore, it provides the user with product and recipe suggestions as well as offer notifications. Another mobile shopping application is aisle $411^{1}$, which enables the consumer to create shopping lists and displays the item's location within the branch. In addition, personalized offers and advertisements can be integrated within the app. As for right now, an LBS app for a Swiss retailer is under way, which should also have similar capabilities. In addition to an indoor navigation, the app will provide context and location aware offers and notifications.

The central question of this paper is to investigate factors, which influence the consumer acceptance of LBS in the context of retail to unfold its potential. There is a vast amount of studies and models on variables affecting the consumer's intention. Some of the most prominent models include the Technology Acceptance Model (TAM), which identifies the perceived usefulness and the perceived ease of use of a system as factors that have a direct effect on the attitude a consumer forms towards it [5]. This attitude eventually determines the actual use. Reference [3] expanded the TAM for handheld Internet devices and appended the perceived enjoyment to the drivers of the consumer's attitude. Specializing on mobile shopping services [13] confirmed the relevance of usefulness and ease of use in this context. Despite the quantity of research available, the special case of LBS in the retail environment has been neglected so far. On grounds of future mobile applications, such as the Swiss retailers, this use case is worth investigating.

\section{THEORY}

LBS delineate services, which take the users' location into account in order to provide them with relevant information. Generally, two types of LBS can be distinguished [8]. The first

\footnotetext{
${ }^{1}$ http://aisle411.com/
} 
type sends location-based information to the device after a prior user request. These kind of services are called Pull-based, whereas their counterpart and second type are Push-based services, which are not triggered by a direct user request. Another possibility to classify LBS is in accordance with their application [6]:

Information/Directory Services provide information on nearby points of interest as; for example, hospitals or restaurants.

Tracking/Navigation Services comprise, for example, navigation systems or directions.

Emergency Services are for instance roadside assistance or police and firemen response.

Location Based Advertising implies activities like mobile coupons, personalized advertising or offers.

\section{A. Mobile Marketing}

Resulting from the pervasiveness of smartphones, the relevance of those devices as far as marketing is concerned is constantly increasing. According to the Mobile Marketing Association (MMA) mobile marketing consists of all activities companies perform in order to use mobile devices and networks as a channel to communicate and interact with consumers [12]. The advantage of mobile marketing lies in the ubiquity of smartphones, which facilitates a virtually constant communication with the user.

Furthermore, the portability of smartphones allows expanding context specific advertising by considering locationbased information of the device; hence creating more personalized marketing messages [6]. This subcategory of mobile marketing is called Location Based Marketing and the advertising activities fall under the term Location Based Advertising (LBA). Analogous to the types of LBS there are Push-based LBA and Pull-based LBA. The MMA gives an overview of several possible marketing strategies, which can be achieved by LBS [12]:

Geo-targeted Text and Display Advertising Placement of advertising messages within mobile media integrating LBS. The promotion message can either be sent to users in a certain geographic area (User Targeting) or to the user's device depending on their location (Message Targeting).

Embedded Icons The personalized advertising is embedded within maps, apps, or on web pages. Icons, or logos of the sponsors are displayed on the map to show the user the relative distance between their location and the sponsor's location.

Search (aka Local Directory Advertising) Used by directory services like the Yellow Pages and provide listings of local companies in regard to proximity to the user's location.

Location Triggered Notifications After an opt-in those services provide advertising messages to the consumer when in a certain range to a merchant or whenever special offers are available.

Location Branded Applications Describe mobile applications, which have a LBS integrated.
Check-in Based Contests and Games User's can “checkin" using the LBS portion of the mobile media to earn rewards such as discounts or mobile coupons depending on their location.

Click-to-X Routing Calls for broad campaigns are being routed to local call centers.

As earlier mentioned, more than half of the purchase decisions are made within the store [14]. Therefore marketing strategies, which focus on the consumers at the act of shopping itself promise to be fruitful. In this context purchases can be divided for example, along the axis of the amount of planning involved anterior to the purchase in spontaneous and deliberate purchases (see Table I) [1]. LBA messages can trigger different purchase behaviors. For instance, mobile coupons delivered depending on the user's position can trigger promotional purchase behavior. However, not only reward based LBA strategies prove to yield results. LBA works with as well as without incentives [16]. Notifying the consumer about a product as they pass by it can possibly cause impulsive purchases. Hence, there are several possibilities in which purchases can be facilitated by considering the consumer's location.

\section{B. Consumer Acceptance}

In the literature there is a great amount of research on the drivers of behavioral intention, whether focusing on technology, or in general. Many models and studies are based upon results of previous investigations; hence being similar to one another and identifying comparable concepts as relevant to consumer acceptance.

TABLE I. PURCHASE BEHAVIOR [1]

\begin{tabular}{|c|c|c|}
\hline \multirow{4}{*}{ 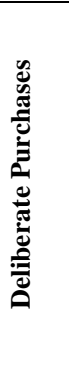 } & $\begin{array}{l}\text { Extended Purchase } \\
\text { Decision Making }\end{array}$ & $\begin{array}{c}\text { Making a purchase based on } \\
\text { objective, logical criteria and for } \\
\text { utilitarian reasons. }\end{array}$ \\
\hline & $\begin{array}{c}\text { Symbolic Purchase } \\
\text { Behavior }\end{array}$ & $\begin{array}{l}\text { Buying a brand to project a certain } \\
\text { image or because it meets with } \\
\text { social approval. }\end{array}$ \\
\hline & $\begin{array}{c}\text { Repetitive Purchase } \\
\text { Behavior }\end{array}$ & $\begin{array}{c}\text { Making a routine purchase or } \\
\text { buying something because you're } \\
\text { loyal to it. }\end{array}$ \\
\hline & $\begin{array}{l}\text { Hedonic Purchase } \\
\text { Behavior }\end{array}$ & $\begin{array}{c}\text { Buying something because you } \\
\text { just like it. }\end{array}$ \\
\hline \multirow{4}{*}{ 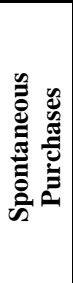 } & $\begin{array}{c}\text { Promotional } \\
\text { Purchase Behavior }\end{array}$ & $\begin{array}{c}\text { Buying something because it's on } \\
\text { sale. }\end{array}$ \\
\hline & $\begin{array}{c}\text { Exploratory } \\
\text { Purchase Behavior }\end{array}$ & $\begin{array}{l}\text { Buying something out of curiosity } \\
\text { or because of a desire for variety. }\end{array}$ \\
\hline & $\begin{array}{c}\text { Casual Purchase } \\
\text { Behavior }\end{array}$ & $\begin{array}{l}\text { Buying something without } \\
\text { thinking much about it. }\end{array}$ \\
\hline & $\begin{array}{l}\text { Impulsive Purchase } \\
\text { Behavior }\end{array}$ & Buying something on impulse. \\
\hline
\end{tabular}

Consumer Technology Acceptance Model The Consumer Technology Acceptance Model (c-TAM) is based on the TAM described and emphasizes the consumer context. The TAM as well as its expansions serve the purpose of trying to explain how consumer acceptance of a technological system in a certain context forms. The model proposed in [3] focuses on handheld Internet devices. The initial factors influencing consumer acceptance are comprised under the term "External Variables" (see Fig. 1). These take the consumer's visual 
orientation as well as the type of device into consideration. Users tending to process information visually find it easier to perform tasks on Internet devices, which is the reason of the causal relation between the consumer's visual orientation and the Ease of Use (EOU). The device itself as well as its characteristics influences the EOU as well, since a bigger screen; for example, facilitates usage. Furthermore, the variable FUN, describing the expected enjoyment of using a system, can vary from device to device. Reference [3] elucidate that handheld devices boost the consumer's intrinsic motivation and hence their enjoyment. In addition, there is a direct influence from the EOU on FUN. This relation results from the notion that the system use is more enjoyable if the user can perform tasks without hindrance emerging from the system itself. On the cognitive level, EOU further influences the Perceived Usefulness (USEF). Usefulness and FUN determine the consumer's attitude towards utilizing the system, which further influences the Behavioral Intention. There have been several studies conducted aiming at determining the prediction of user behavior. Reference [13] for example, focused on mobile services in their research. According to the study, issues concerning the screen size and therefore worse readability have become irrelevant to a certain point. However, obstacles such as economic factors preventing a widespread reachability through mobile services remain. Following TAM it can be shown that USEF, as well as EOU positively influence the acceptance of mobile phones in the retail environment [13].

Quality of Service Three key factors were established in having an influence on consumer acceptance of mobile Internet services: service quality, satisfaction, and value [17]. Upon mobile applications, Quality of Service was identified as a criterion for app acceptance [18]. The Quality of Experience can be partially ascribed to the design. Research results point to the assumption that especially the interfaces as well as the interaction with the app play a role in the perception of app design [10].

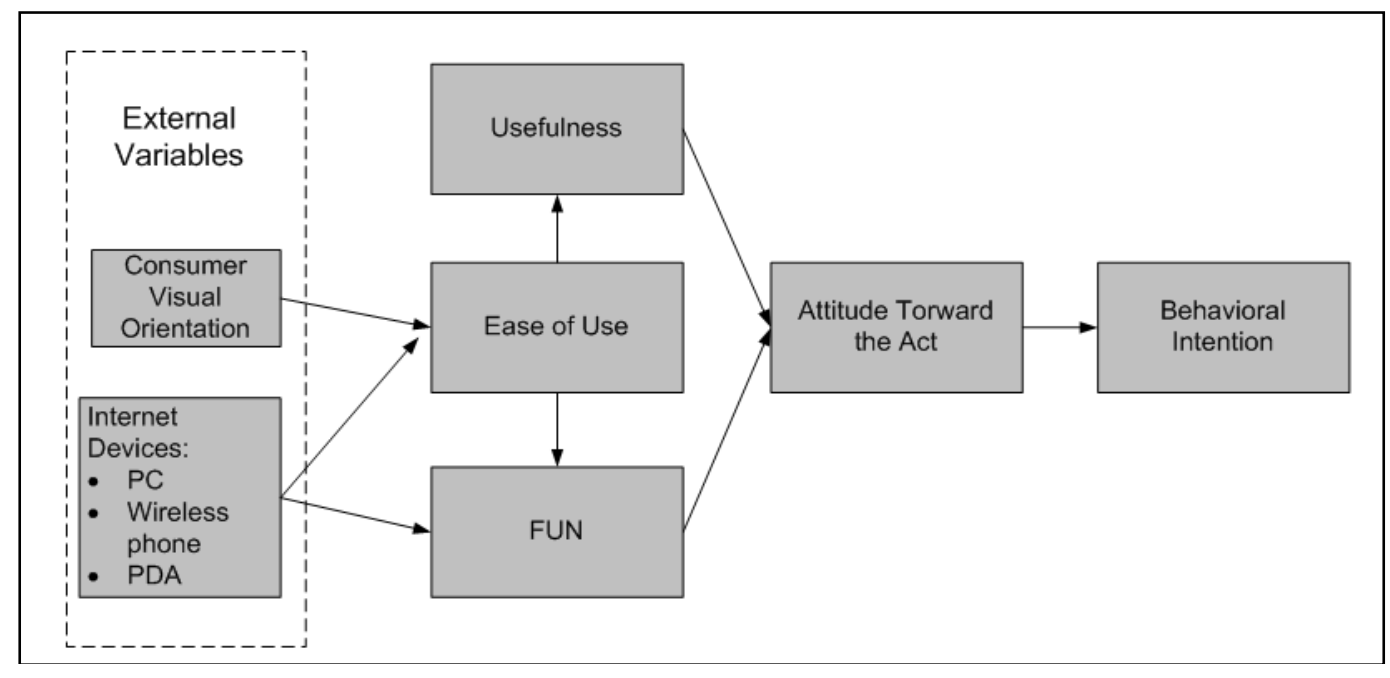

Fig. 1. c-TAM

Utilitarian/Hedonic Performance Expectancy The consumer's attitude towards services; hence, the behavioral intention to use those services, is determined by two expectations. On the one hand, the Utilitarian Performance Expectancy in this context includes variables like flexibility or effectiveness of the services. On the other hand, there are Hedonic Performance Expectancies, which consider the enjoyment, the user experiences, while using the service. Furthermore, Effort Expectancy, associated with the work necessary to use the service, influences Utilitarian as well as Hedonic Performance Expectancy. Besides, those Social Influences and Facilitating Conditions affect the intention [20].

Motivation Theory Reference [9] investigated the acceptance of LBS in regard to the motivation theory. It was shown that intrinsic motivation, which subsumes the enjoyment of usage, influences the consumer's intention to a greater extent than extrinsic motivation. Pressure or incentives are attributed to extrinsic motivation. In addition it was shown that the initial extrinsic motivation does not allow drawing conclusions with respect to further application.
Value The value is described as the balance between benefits and risks. The risks in the context of LBS lay within the sharing of the user's position. The benefits are, for example, personalized offers [16]. The personalization of offers was found to positively influence the consumer's attitude [11]. Furthermore, entertainment has a positive influence on attitude.

Critical Success Factors In [4] a study was conducted identifying several critical success factors for LBS. In the first portion of the study, the participants were to name factors important regarding LBS. The criterion named most often by the test subjects within the brainstorming sessions was privacy. Privacy concerns about LBS are one of the most prominent factors, which have a negative influence on the consumer acceptance. In the context of privacy Personalization Privacy Paradox is described as following [19]: As personalization improves, concerns in regard to privacy increase. Hence, the consumer acceptance decreases. Reference [14] identified the disclosure of the user's home as the greatest concern. The second portion of the study was designed to rank the most frequently named factors of the first portion in a quantitative 
survey. The ranking of the fifteen examined factors are displayed in Table II.

TABLE II. CRITICAL SUCCESS FACTORS AND RANKING [4]

\begin{tabular}{|l|l|}
\hline Critical Success Factors \\
\hline 1. Speed & $\begin{array}{l}\text { 9. Smart Location-Based } \\
\text { Services }\end{array}$ \\
$\begin{array}{l}\text { 2. Real-Time/Up-To-Date } \\
\text { Information }\end{array}$ & $\begin{array}{l}\text { 10. Aesthetics } \\
\text { 3. Cost }\end{array}$ \\
11. Quality of Reviews \\
4. Usefulness & $\begin{array}{l}\text { 12. Integrated } \\
\text { Applications/Services }\end{array}$ \\
5. Simple/Ease of Use & $\begin{array}{l}\text { 13. Standards \& Platform } \\
\text { Independence }\end{array}$ \\
6. Reliability & 14.Size of Application \\
7. Personalization/ Preference & 15. Publicity of Location- \\
Setting & Based Services \\
8. Privacy & \\
\hline
\end{tabular}

The discrepancies within the first and second part might be resulting from the focus on different age groups. Most of the participants of the brainstorming sessions were between 36 and 40 years old and had achieved a doctor's degree. In contrast to the first portion of the research, where mostly test subjects between the ages of 15 and 25 years participated.

\section{METHOD}

\section{A. Grounded Theory}

The qualitative research approach Grounded Theory was chosen so as to investigate the research question. A study conducted in accordance with the Grounded Theory origins from an initial data collection from sources varying in their characteristics. Once the initial data collection is completed, codes for the data are developed. Coding is used to find significant portions of information within the data and connecting those into concepts and categories. After the extraction of the concepts and categories, those are used to write memos and derive hypotheses relevant to the research area. Those hypotheses, however, have to be verified. Therefore, new data are collected and coded. Furthermore, it has to be determined to which extent the theories can be confirmed by the new data. In accordance with [7], if discrepancies occur between the data and the theories the theories have to be adjusted. The cycle of collecting and coding data, developing theories, and verifying those based on new data is called Theoretical Sampling and is repeated until theoretically there is no more information gain possible. This state is known as the Theoretical Saturation. A schematic overview of the Grounded Theory is shown in Fig. 2.

\section{B. Data Collection}

Vol. 4, No. 12, 2013

The data collection method used within this study was a General Interview Guide Approach as described in [15]. The interview guide was revised at the end of each Theoretical Sampling Iteration in order to verify the developed theories. Fifteen participants were interviewed. The interviews consisted of four parts:

Background Information The first portion of the conversation was used to collect demographic data.

Smartphone Usage The second part was concerned with the participant's experience with smartphones. For example, they were asked to name criteria of good mobile applications and what has been bothering them about apps they have already used (e.g. "Which factors compose a 'good' app in your opinion?").

Buyer Behavior The third part consisted of questions concerning their buying behavior. For instance, the test subjects were asked whether their buying behavior had changed over the past years and if so, which environmental factors had caused those changes (e.g. "Would you say that your buying behavior has changed within the last couple of years? If so, which factors have been responsible for those changes?").

Shopping Apps The last portion of the interview covered the participant's opinion about mobile applications in the retail environment, focusing on LBS in more detail. Therefore, several scenarios were presented to the interview partners. In those scenarios the participants were grocery shopping and used a smartphone shopping app, which allowed them; for example, to create a mobile shopping list, showed them different kinds of offers or navigated them to products found on their shopping list. After each scenario the subjects where asked about different parts of the scenario and their receptive perception (e.g. "Imagine the following scenario: You are grocery shopping in your usual supermarket to buy the following items: Milk, Tea, Baking Powder, Canned Corn, Chocolate. You probably know where those products are located within your supermarket. Furthermore, imagine that you do not have a handwritten shopping list, but an app, which contains a mobile version of the shopping list. Would you like to receive offers of this branch on your smartphone or would this bother you? Would you like to receive offers of the items on your shopping list on your smartphone or would this bother you? Would you be interested in offers of items on your shopping list but from different brands?"). 


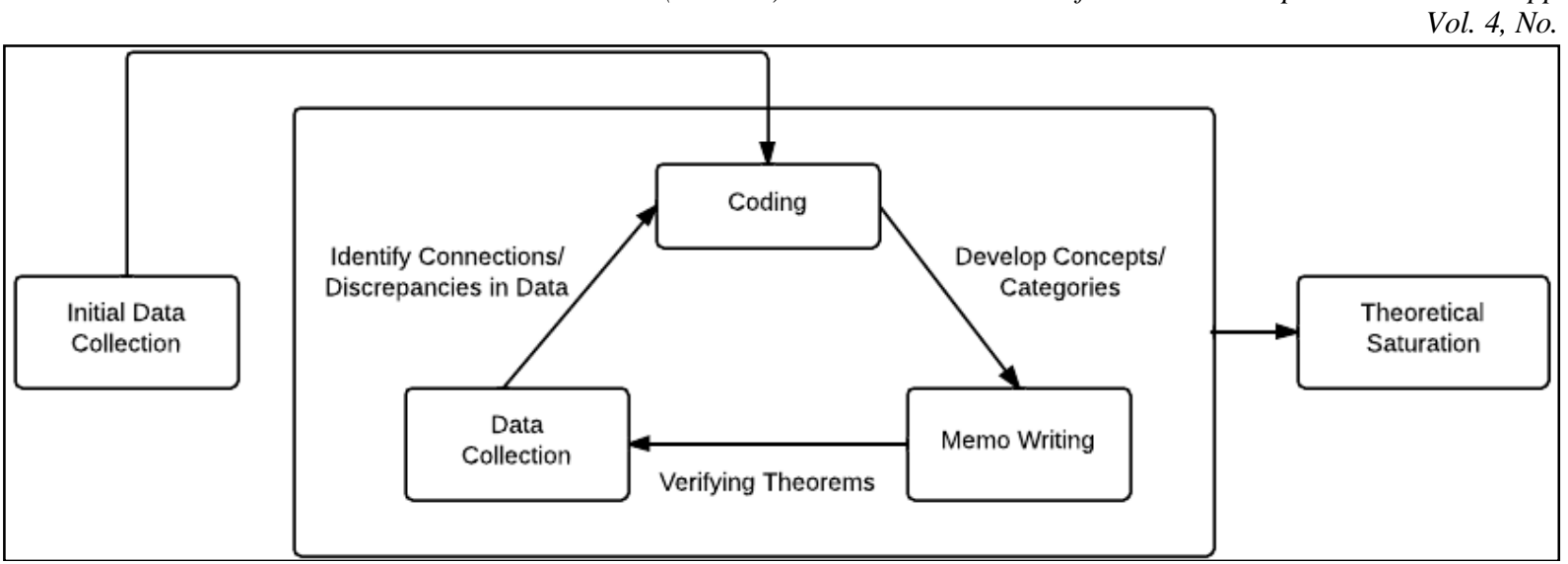

Fig. 2. Grounded Theory schema

Towards the end, the participants were asked to rank eight different factors in accordance with their importance concerning a shopping app as described in the scenarios. The most important factor should be ranked first and the least crucial one last. ("Within the

context of the scenarios, please rank the following factors according to their importance for a shopping app and please explain your ranking: Usability, Cost, Reliability, Speed, Design, Usefulness, Battery Consumption, Up-To-Date Information.").

\section{Research Process and Hypotheses}

Fig. 3 gives an overview of the research process. Throughout the study different hypotheses were developed from the insights obtained out of the data collection. In the process of verifying these resulting from a larger amount of information from the newly acquired data some of the hypotheses have been refined throughout the study. Furthermore, as a result of the new findings, the interview guide was adjusted at the end of each iteration to accommodate for those modifications. All in all twenty-one theorems were laid down. The ten most prominent are mentioned in Table III.
TABLE III. HYPOTHESES

\begin{tabular}{|c|c|}
\hline $\mathrm{H}^{\prime}$ & $\begin{array}{l}\text { The buyer behavior changed within the last years for most } \\
\text { consumers; however, no clear tendencies can be observed. }\end{array}$ \\
\hline H3 & $\begin{array}{l}\text { Shopping apps in the retail environment are not } \\
\text { widespread; consumers prefer traditional shopping lists to } \\
\text { mobile shopping lists. }\end{array}$ \\
\hline H6' & $\begin{array}{l}\text { Consumers have a positive perception of offers of the } \\
\text { branch as well as for items on their shopping list. }\end{array}$ \\
\hline H7 & $\begin{array}{l}\text { Offers concerning items of the shopping list but from other } \\
\text { brands are accepted by most of the consumers }\end{array}$ \\
\hline H8' & $\begin{array}{l}\text { Consumers feel ambivalent about offers customized to the } \\
\text { consumer's purchase behavior. }\end{array}$ \\
\hline H9 & $\begin{array}{l}\text { Privacy concerns in regard to the app do not determine the } \\
\text { consumer acceptance. }\end{array}$ \\
\hline H12' & $\begin{array}{l}\text { Navigation is perceived as helpful within unknown branches } \\
\text { and under time pressure. However, some of the consumers } \\
\text { determine the relevance of the navigation regarding the size } \\
\text { of the branch. }\end{array}$ \\
\hline H15 & $\begin{array}{l}\text { Usability is the most crucial factor influencing the } \\
\text { consumer's perception of a 'good' app. }\end{array}$ \\
\hline H17 & $\begin{array}{l}\text { Apps have to be reliable; otherwise, the consumer is } \\
\text { frustrated. }\end{array}$ \\
\hline H21' & $\begin{array}{l}\text { The more an app fulfills the crucial factors; the more the } \\
\text { consumers are willing to cut back on less important criteria. }\end{array}$ \\
\hline
\end{tabular}

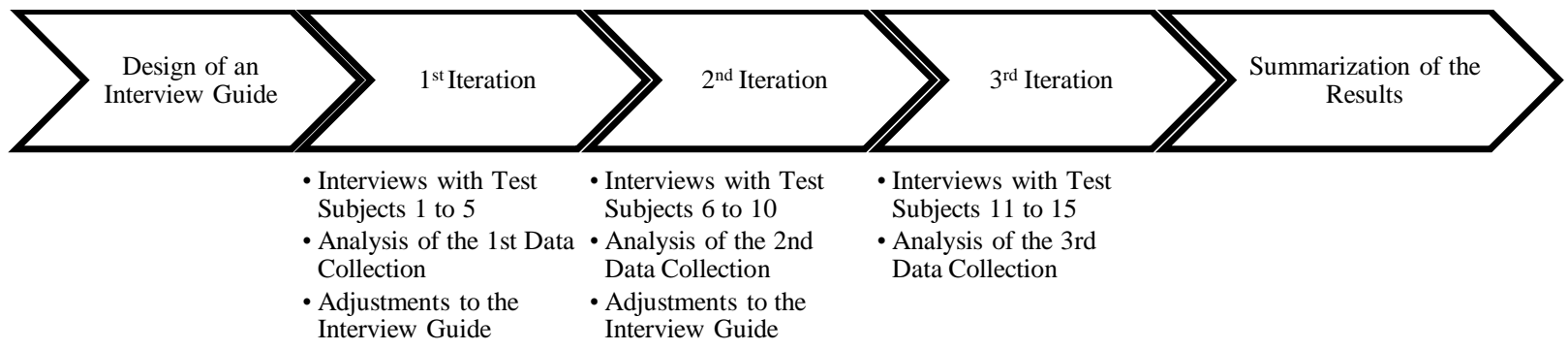

Fig. 3. Research process

\section{RESUlts}

\section{A. Participants}

Three iterations of the Theoretical Sampling cycle were conducted. Within each iteration five participants were interviewed; this corresponds to a total of 15 test subjects ( 7 female, 8 male). Further $53.3 \%$ of the participants had obtained some kind of degree within a technological field. As shown in Fig. 4, most of the participants were between 20 to 29 years old at the time of the study. The focus on this age group is, on the one hand, due to the greater adoption of technology within younger age groups. On the other hand, consumers younger than this usually have no household of their own and therefore do not necessarily have a distinct buying behavior in regard to groceries on which this study focused. 


\section{B. Hypotheses}

All the hypotheses presented in this paper could be confirmed. However, this is resulting from the adjustments of the theories necessary through the review of newly collected data. Refined hypotheses are marked with an apostrophe (e.g. $\mathrm{H} 2$ ').

Buyer Behavior (H2') All except three test subjects confirmed that their buying behavior has changed within the last couple of years. However, within this study there was no general tendency regarding the way the behavior has changed. The answer mostly given was that the participants purchase different items than before, for example, due to a changed life style, or more cost-effective items based on budgeting concerns. Two out of the three test participants which did not observe a change in their buying behavior were living in a household where they were neither responsible for the grocery shopping itself nor for the financial planning of the expenses.

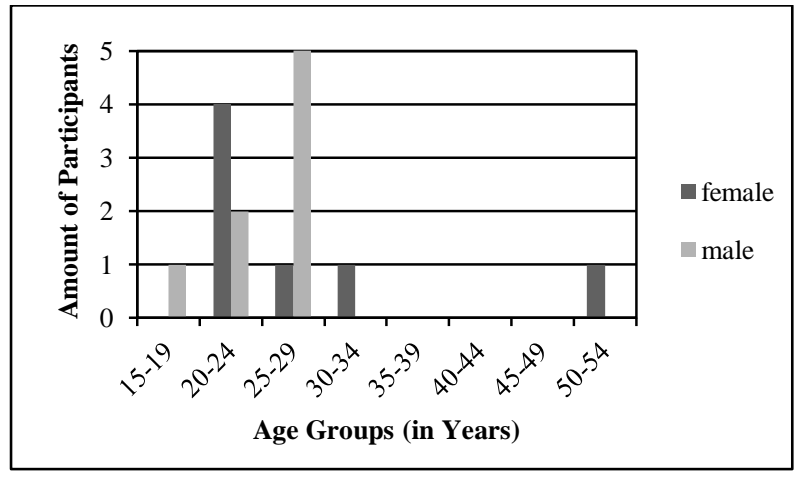

Fig. 4. Overview of participants

Shopping-Apps (H3) None of the interviewed subjects used any of the available mobile apps local retailers provide. The reasons named were that either the participants were unfamiliar with the existence of such apps, or they perceived the available apps as useless. Throughout this section participant commentaries are italicized in this portion of the paper and were translated from the interview transcripts.

"Well, in regard to mobile shopping lists, because for me they are too cumbersome and I am faster using a piece of paper and writing down my products than opening the app and typing them in using the keyboard on the smartphone ... And, yeah, I have not found a benefit in the apps of the retailers. But, I have to admit that I have not tried them out yet."

Offers (H6', H7, H8') In regard to the offers made available through a shopping app the perception of the consumers depend on the kind of offer made. An overview of the acceptance of different kinds of offers is depicted in Fig. 5. Eight of the participants would be interested in receiving offers of the branch in which they are shopping and twelve would like to receive offers which are customized to their shopping list (H6').

In regard to items of the shopping list from other brands more than half of the participants would be interested. However, some of the subjects pointed out that the item itself plays a role in whether an offer would be accepted or not. For instance, dairy products are one of the food categories, which created a greater brand loyalty than others within this study (H7).

“... it would be important to me, I don't know, if I for example think about dairy products or eggs, there I, it is important to me that it is a renowned brand. However, I would not care about chocolate."

All the test subjects confirmed that offers of the products regularly purchased are useful and are perceived in a positive way. This, however, is not true for a certain scenario in which the participants were presented with the offer of an item, regularly purchased by them although not on the shopping list, as they pass by this specific item in the grocery store. Eight of the participants perceived this as an invasion of privacy or just generally negative. Although not all the test subjects were interested in every kind of offer, the negative perception of those offers was low among the subjects except for this one.

"The emotion in regard to this is ambivalent; of course, it would be practical to be reminded, since the supply of different groceries is coming to its end, on the other hand, this [reminder] would be a paternalism, which would probably start being unpleasant."

However, the option of setting preferences in receiving offers was widely accepted and found useful by the questioned participants (H8').

Privacy (H9) Twelve of the subjects had no serious concerns in regard to their privacy being invaded by the shopping app presented in the scenarios in general. Except for three participants, who would decide if they would use the app after reading the terms of use.

"As for right now my concerns would be minor, since I don't believe that any tenuous information could be derived..."

Navigation (H12') The navigation within a grocery store was perceived as helpful by all but two participants. Some of the test subjects, however, can only imagine using it within unknown stores, when they are under time pressure or stores with a great sales area.

"Well, that would be helpful. Very often I have been shopping in stores, and I could not find certain items and had to find employees to ask them where this product is and the employees did not know exactly where to find the item either and then this could really facilitate this if it would really work and tell me at least in which aisle it should be located or show me the way to the location. However, it would be very bothering if the item was not at that location..."

Factors (H15, H17, H21') Different factors influencing consumer acceptance were identified before as well as during the study. At the beginning of the interviews all fifteen participants were asked to name factors, which according to their opinion characterize a good app. The amount of participants naming a specific factor is shown in the last column of Table IV. Eight factors were identified through the most prominent results of the first iteration as well as drivers found in the literature. 


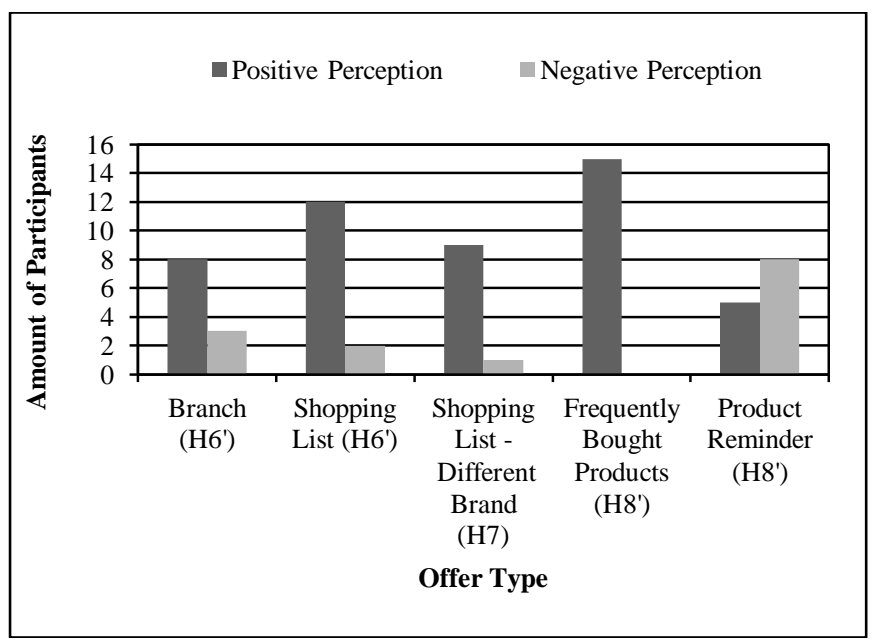

Fig. 5. Consumer acceptance of offers
The test subjects of the second and third iteration were asked to rank those eight factors in regard to their importance for a shopping app as described in the scenarios presented to them before. Those answers determined the ranking as well as the rank of the factors available in the first and third column of Table IV.

Usability was the highest ranked factor as well as named by all except one participant. Besides this clear ranking, when asked, which factors are somewhat interchangeable, Usability was named by several participants as not interchangeable. Reliability and Usefulness reached the same ranking. However, Usefulness was named fewer times by the participants.

"Another reason, when apps crash then I normally just leave them and not open them a second time"

"Usability is also important to me, I believe that it is not enjoyable when you use an app and have no idea on how to use it."

TABLE IV. EVALUATION OF FACTORS INFLUENCING ACCEPTANCE

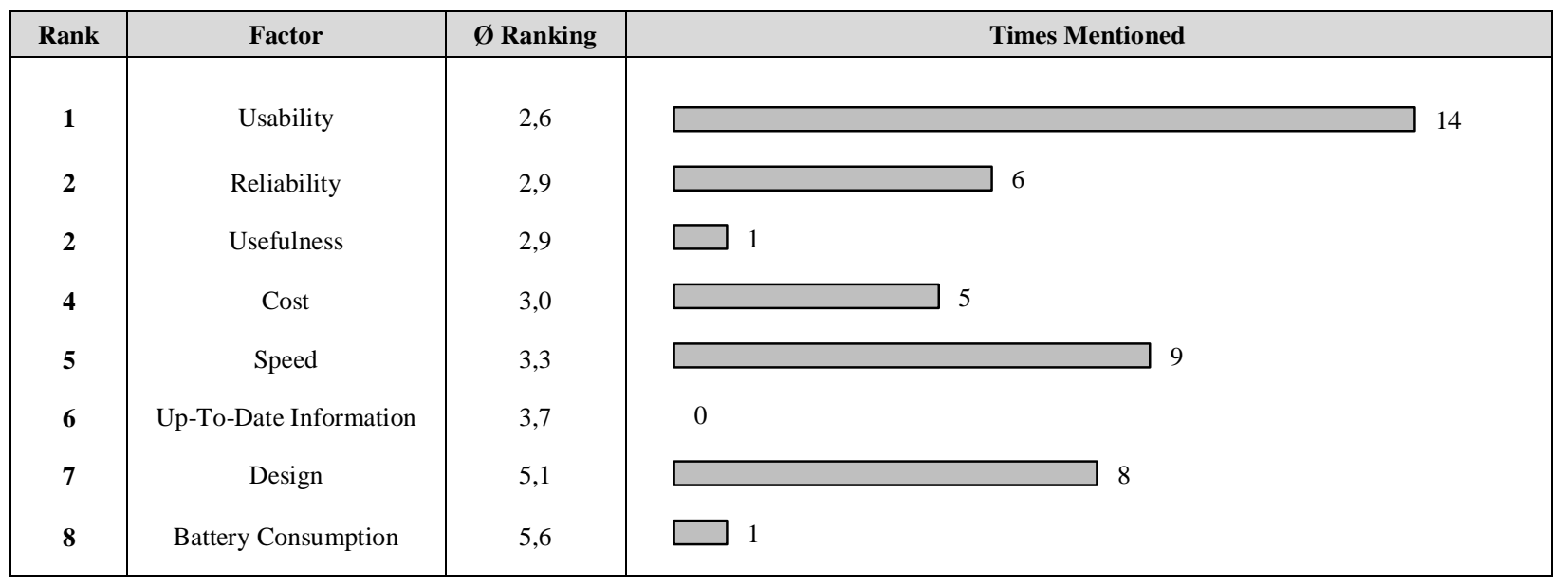

\section{Discussion AND CONCLUSION}

The general notion from this study is that consumers within the investigated age group would accept a LBS application in the context of retail. Throughout the literature on technology acceptance in general, on LBS or on mobile services a few factors are similar amongst the models and theories. Taking the c-TAM as a starting point, the three crucial factors influencing the consumers' attitude hence determining their intention to utilize a system are usefulness, ease of use, and fun. The usefulness of a system was identified as a critical variable in many studies, although the concept was being delivered under different terms. Regarding the motivational theory, for example, some of the characteristics of usefulness can be ascribed to extrinsic motivation. Utilitarian Performance Expectancy is another similar variable determining attitudes towards technology. Besides, regarding the results found within the literature, the conducted study confirmed the importance of usefulness within the context of LBS in retail as the second most prominent factor identified. The factor of reliability is also accounted to usefulness.
Reference [3] included the ease of use within their model. The concept was processed within the study under the term of the usability of the proposed application. Besides, the extensive research done in the field of the EOU as a critical factor in influencing behavioral intention in different fields of expertise [13] as well as the study conducted confirmed its eligibility for mobile shopping services.

Comparing the results from this study to [4] it is clear to see that even though the ranking of the factors is not exactly equivalent, the six most crucial factors are the same in both studies as can be seen in Table V.

The factor of fun or enjoyment was not investigated within this study. The only mention of this within the conducted study focused on the effect reliability as a software quality characteristic has on the user enjoyment. However, different literature sources suggest that enjoyment, intrinsic motivation, or hedonic performance expectancy does play a role. 
TABLE V. FACTOR RANKING OF THE STUDY IN COMPARISON TO [4]

\begin{tabular}{|c|c|c|}
\hline Factor & Rank Study & Rank [4] \\
\hline Usability (Ease of Use) & 1 & 5 \\
\hline Reliability & 2 & 6 \\
\hline Usefulness & 2 & 4 \\
\hline Cost & 4 & 3 \\
\hline Speed & 5 & 1 \\
\hline $\begin{array}{c}\text { Up-To-Date } \\
\text { Information }\end{array}$ & 6 & 2 \\
\hline Design & 7 & 10 \\
\hline Battery Consumption & 8 & - \\
\hline
\end{tabular}

In the literature, the concepts vary among the authors in the sense that the terms describe similar drivers, variables of one theory merge within different factors of others and some characteristics of the concepts are disregarded in some studies whereas they are the focal point of others. However, the general idea of the dominant factors from the point of the study conducted as well as the review of the literature is best described by the c-TAM as well as its predecessors, which were not mentioned in detail within this paper.

The factor privacy was not a determining factor of usage within this study. This might be due to two reasons. First, the app described within the scenarios is an example of a pullbased LBA strategy. Those tend to create fewer privacy concerns than their counterparts. The second reason might be ascribed to the fact that the determining of the location was solely conducted within the store. Reference [14] showed that the greatest privacy issue for consumers is the disclosure of their home, this use case has no relevance within the study.

Regarding the scenarios delivered to the participants, the most prominent finding was that the acceptance of personalized offers depends on the context in which the shopper is as well as on the way the offer is delivered. Hence the point where the positive perception of a buying suggestion shifts towards a negative notion is worth investigating further.

With regard to future research, other factors known from the literature like fun and social influences should be investigated in the context of location-aware apps in retail. Further research on the findings of this study with different age groups would provide a more general picture of the research field.

\section{REFERENCES}

[1] Baumgartner, H., "Toward a Personology of the Customer", Journal of Consumer Research, vol. 29, no. 2, 2002, pp. 286-292.

[2] Bhattacharya, S., Floréen, P., Forsblom, A., Hemminki, S., Myllymäki, P., Nurmi, P., Pulkkinen, T., and Salovaara, A., "Ma\$\$iv€ - An Intelligent Mobile Grocery Assistant", 8th International Conference on Intelligent Environments Guanajuato, Kune, 2012, pp. 165.
[3] Bruner II, G.C., and Kumar, A., "Explaining consumer acceptance of handheld Internet devices", Journal of Business Research, vol. 58, no. 5, 2005, pp. 553-558.

[4] Chin, N., "Critical Success Factors of Location-Based Services", Dissertation, University of Nebraska-Lincoln, 2012.

[5] Davis, F.D., "A technology acceptance model for empirically testing new end-user information systems: theory and results", Dissertation, Massachusetts Institute of Technology, Sloan School of Management, 1985.

[6] Dhar, S., and Varshney, U., "Challenges and business models for mobile location-based services and advertising", Commun.ACM, vol. 54, no. 5, 2011, pp. 121-128.

[7] Flick, U., von Kardorff, E., and Steinke, I., Qualitative Forschung - Ein Handbuch, 7th edn, Rowohlt Taschenbuch Verlag, Hamburg, 2009.

[8] Hilty, L., Oertel, B., Wölk, M., and Pärli, K., Lokalisiert und identifiziert. Wie Ortungstechnologien unser Leben verändern., 1 st edn, Vdf Hochschulverlag, Zurich, 2012.

[9] Ho, S.Y., "The effects of location personalization on individuals' intention to use mobile services", Decision Support Systems, 2012.

[10] Ickin, S., Wac, K., Fiedler, M., Janowski, L., Jin-Hyuk Hong, and Dey, A.K., "Factors influencing quality of experience of commonly used mobile applications", Communications Magazine, IEEE, vol. 50, no. 4, 2012, pp. 48-56.

[11] Lee, Y., "Factors influencing attitudes towards mobile location-based advertising", Software Engineering and Service Sciences (ICSESS), 2010 IEEE International Conference on, 2010, pp. 709.

[12] Mobile Marketing Association, "Mobile Location Based Services Marketing Whitepaper", Mobile Marketing Association, 2011.

[13] Shankar, V., Inman, J.J., Mantrala, M., Kelley, E., and Rizley, R., "Innovations in Shopper Marketing: Current Insights and Future Research Issues", Journal of Retailing, vol. 87, Supplement 1, 2011, pp. $29-42$.

[14] Tsai, J., Kelley, P.G., Cranor, L.F., and Sadeh, N., "Location-Sharing Technologies: Privacy Risks and Controls", TPRC, 2009.

[15] Turner, D.W., "Qualitative Interview Design: A Practical Guide for Novice Investigators", The Qualitative Report, vol. 15, no. 3, 2010, pp. 754-760.

[16] Unni, R., and Harmon, R., "Perceived effectiveness of push vs. pull mobile location-based advertising", Journal of Interactive Advertising, vol. 7, 2007, pp. 1-24.

[17] Vlachos, P.A., and Vrechopoulos, A.P., "Determinants of behavioral intentions in the mobile internet services market", Journal of Services Marketing, vol. 22, no. 4, 2008, pp. 280-291.

[18] Wac, K., Ickin, S., Hong, J., Janowski, L., Fiedler, M., and Dey, A.K., "Studying the experience of mobile applications used in different contexts of daily life", Proceedings of the first ACM SIGCOMM workshop on Measurements up the stack ACM, New York, NY, USA, 2011, pp. 7.

[19] Xu, H., Luo, X., Carroll, J.M., and Rosson, M.B., "The personalization privacy paradox: An exploratory study of decision making process for location-aware marketing", Decision Support Systems, vol. 51, no. 1, 2011, pp. 42-52.

[20] Yang, K., "Determinants of US Consumer Mobile Shopping Services Adoption: Implications for Designing Mobile Shopping Services", Journal of Consumer Marketing, vol. 27, no. 3, 2010, pp. 262- 270. 